\title{
Intra-Atrial Tunneled Dialysis Catheter as Vascular Access: Ultimate Choice in a Hemodialysis Patient
}

Ikram Mami' ${ }^{1}$, Soumaya Mekki ${ }^{1}$, Jalel Ziedi², Imtinene Ben Mrad ${ }^{3}$, Mleyhi Sobhi² ${ }^{*}$, Malek Ben Mrad ${ }^{2}$, Hela jebali ${ }^{1}$, Hiba Ghabi ${ }^{1}$, Lamia Rais $^{1}$, Soumaya Beji ${ }^{1}$, Lilia Ben Fatma ${ }^{1}$, Faker Guedira ${ }^{2}$, Raouf Denguir ${ }^{2}$, Karim Zouaghi ${ }^{1}$.

${ }^{1}$ Nephrology, Dialysis and Kidney Transplantation Department. La Rabta Teaching Hospital, Faculty of medicine of Tunis, University of Tunis El Manar, Tunisia.

${ }^{2}$ Cardiovascular Surgery Department. La Rabta Teaching Hospital, Faculty of medicine of Tunis, University of Tunis El Manar, Tunisia

${ }^{3}$ Cardiology Department. Hbib Thameur Hospital. Faculty of medicine of Tunis, University of Tunis El Manar, Tunisia

*Corresponding Author: Sobhi Mleyhi, Department of cardiovascular surgery, La Rabta Hospital, Jabbari Street 1007 Tunis, Tunisia

Received Date: September 28, 2021; Accepted Date: October 11, 2021; Published Date: October 18, 2021

Citation: Ikram Mami, Soumaya Mekki, Jalel Ziedi, Imtinene Ben Mrad, Mleyhi Sobhi, et al. (2021) Intra-Atrial Tunneled Dialysis Catheter as Vascular Access: Ultimate Choice in a Hemodialysis Patient. J. General medicine and Clinical Practice, 4(1); Doi:10.31579/2639-4162/053

Copyright: (C) 2021 Sobhi Mleyhi, This is an open-access article distributed under the terms of the Creative Commons Attribution License, which permits unrestricted use, distribution, and reproduction in any medium, provided the original author and source are credited.

\begin{abstract}
:
Recurrence of complications related to usual vascular access leads to exhausted vasculature. Several options were described in similar cases like tans-lumbar catheter and intra-atrial tunneled dialysis catheter.

We report the case of a 22-year-old- male, with kidney failure, anuria and exhausted vasculature. Emergent kidney transplantation was not suitable to his case. We decided to combine peritoneal dialysis with once-a-week hemodialysis using a tans-lumbar tunneled catheter at first time, then an intra-atrial tunneled dialysis catheter as vascular access of last resort.

Development of renal replacement therapy expose nephrologist to new challenges. Working on alternative therapy is inspiring, but rationalizing exploitation of current options meanwhile is imperative.

Keywords: end-stage renal disease; hemodialysis; trans-lumbar tunneled catheter; intra-atrial tunneled dialysis catheter or deleterious treatment
\end{abstract}

\begin{abstract}
Abbreviation's list:
AVF: arteriovenous fistula

AVG: arteriovenous graft

CVC: central venous catheters

IATDC: intra-atrial tunneled dialysis catheter

TDC: tunneled dialysis catheters
\end{abstract}

TLDC: translumbar tunneled dialysis catheter

RRT: renal replacement therapy

PD: peritoneal dialysis

HD: hemodialysis

\section{Introduction:}

Hemodialysis (HD) is the major modality of renal replacement therapy requiring an adequate vascular access as arteriovenous fistula (AVF).
However, recourse to central venous catheters (CVC) is often necessary in adult patients. For children as well, age-related anatomical limitations and expectations for early transplantation were correlated with CVC preference up to $30 \%$ at dialysis initiation [1]. The use of dialysis catheters induces at many times venous stenosis and occlusion exposing to vascular access loss and exhaustion of conventional vascular access [2, $3]$. This point is not clearly defined, and depends on institutions and surgical practices $[4,5]$. Consequently, the prevalence of hemodialysis patients with exhausted vasculature is not established yet, but seem to be increasing.

The management of end-stage renal disease patients includes continuous researches to improve both life-expectancy and life-quality in this population. Then, unconventional tunneled dialysis catheters (TDC) have been reported in patients with no upper and lower body venous access including different sites as: translumbar, transhepatic or transrenale. [6]

Intra atrial tunneled dialysis catheter (IATDC) is a vascular access reserved at last resort and salvage therapy. Only, a few cases or small series were reported in the literature [7]. We report an exceptional case of combined peritoneal dialysis (PD) to HD used translumbar and IATDC. 


\section{Case report:}

A 22-year-old- male with end-stage renal disease (ESRD) undergoing dialysis, was admitted at first time in our department for vascular access exhaustion 3 years ago.

In childhood, he was diagnosed with ureteropelvic junction obstruction, and vesicoureteral reflux. Then, he developed a kidney failure and ended up on dialysis at fourteen.

Then, he was referred to our department at the age of 20 for exhausted vasculature. At that time, he had required several tunneled and nontunneled venous catheters in femoral and jugular sites, three AVF and two arteriovenous graft (AVG). Considerable attempts to get adequate venous access in usual sites failed.

Computed tomography scans and angiographies showed thrombosis of both subclavian veins extended to superior vena cava. Further imaging confirmed thrombosis of both femoral venous. Etiological investigations didn't reveal thrombophilia.

A translumbar tunneled dialysis catheter (TLDC) has been inserted in

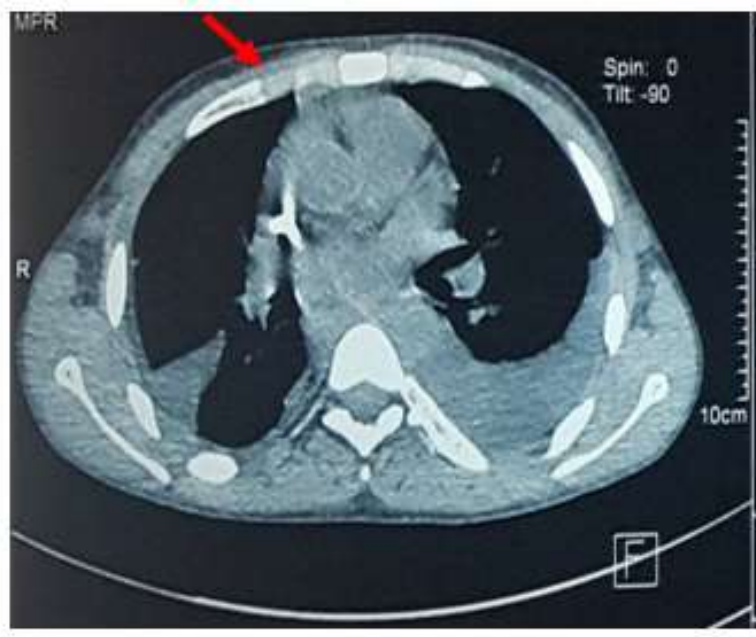

extreme emergency by cardio vascular surgeon. Because of the poor outcomes of unconventional TLDC, peritoneal dialysis was combined to once weekly hemodialysis. Icodextrin was used as peritoneal solution because of anuria. In less than a year, trans-lumbar catheter was removed for dysfunction. Computed Tomography scans confirmed persistent superior vena cava and an inferior vena cava thrombosis. Renal transplantation was discussed but considered as not appropriate.

Fourteen months ago, he was admitted for severe septicemia and was treated with broad-spectrum antibiotics. During hospitalization, patient had edema, hyperkalemia and severe anemia requiring urgent hemodialysis. The use of intra-atrial tunneled dialysis catheter (IA TDC) as vascular access was indicated by cardiovascular surgeons as salvage therapy.

The surgery was carried out under general anesthesia by a right anterior thoracotomy. After opening the pericardium, the catheter was placed in the right atrium, fixed and tunneled [Figure 1et 2]. When closing the various incisions layer-by-layer, double tube was inserted in the pericardium and pleural cavity to drain possible hemorrhage, while the cuff was put in the chest wall.

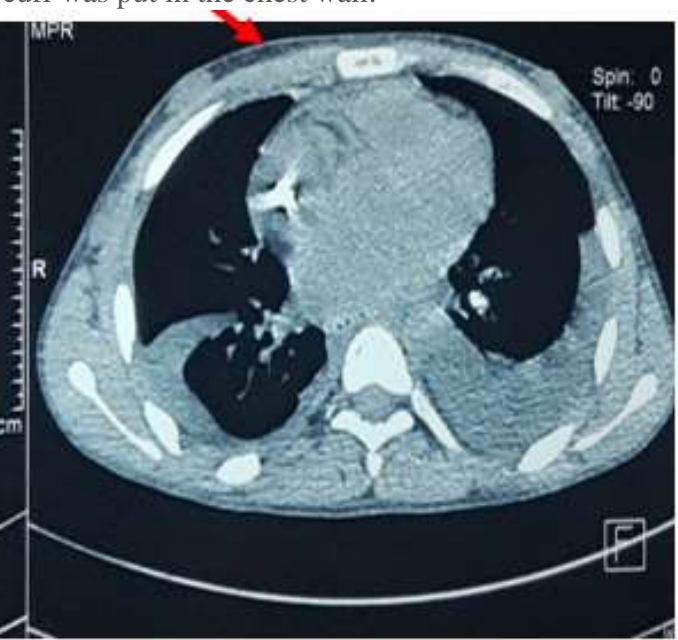

Figure1: Computed tomography of the chest showing direct right atrial catheter insertion (red arrow) 
Throughout four weeks, an infection related to IA TDC was reported with favorable outcome.

Nine months later, PD catheter became not functional after severe peritonitis and was removed.

\section{Discussion:}

Nearly 2.3 million people worldwide depend on HD [8]. Despite progress, vascular access remains the weak chain in HD adequacy, and a critical determinant of median survival and life quality for HD patients. All guidelines recommend creation of AVF followed by AVG and CVC at last.

However, CVC are increasingly used as a temporary option pending AVF maturation, or as a permanent alternative after expiration of different possibilities. In fact, according to the Annual Data Report of end stage renal disease in the United States, $80 \%$ of patients used a tunneled central venous catheter at hemodialysis initiation, $17 \%$ used a fistula, and 3\% a graft; 90 days after dialysis initiation, $69 \%$ of the patients were still using a catheter [9].

Infections and thrombosis, as the main complications related to CVC, lead to a loss of vascular access in the relevant vein respectively in $10 \%$ and 30 to $40 \%[10,11]$. Consequently, many patients, like ours, exhaust their veins.

When conventional venous sites as internal jugular, femoral and subclavian are exhausted, several unconventional catheters have been used in the literature as alternative solution like translumbar, transhepatic, trans-renal, great saphenous, azygous, hemi-azygous veins [6, 12, 13]. Rahman S. and al. reviewed technical challenges and complications of common unconventional dialysis catheter [14]. The highest incidence of immediate and early complications was recorded with transhepatic catheter. Although the overall morbidity and mortality was at higher rate comparing to traditional TDC, different technique proved efficiency and extended patients 'life few months to several years.

In our case, TLDC was used in first time because of thrombosis of superior vena cava but lasted less only one year. Lund and al. described initially this alternative in 1995 [15].The main complications affecting significantly the median survival were infection and catheter dysfunction. However, prevalence of problems related to central venous catheter are significantly more important with TLDC. Recent studies reported that $41.6 \%$ of patients presented a catheter-related first infection after $98 \pm$
72.1 (6-201) days and estimated long-term patency at 12 months was $45 \%$. $[13,16]$. This type of catheter can be considered as a safe, temporary alternative access for selected hemodialysis patients with exhausted vasculature [13]

Our patient had another type of unconventional TDC as IATDC after both superior and inferior vena cava thrombosis. At that time, it was the only solution to maintain him alive. This technique was first reported by Chavanon et al. in 1999 [17]. Since then, other case reports and small series recorded similar illustrations [18-21].

Recently a systematic review included 51 patients with IATDC [7]. All the patients had exhausted conventional vascular accesses. All IATDCs were put by cardiovascular surgeons following the same method described in our case report. [7]

In the same review, six patients developed IATDC-related sepsis. At the end of follow-up, 13 patients died: seven patients died within 15 days following IATDC insertion: 3 catheter related deaths and 1 septic shock. Six additional patients died later than 15 days not related to catheters. Median survival time in patients with IATDC was 25 months, lower than conventional TDC which was 36 months $[7,22]$.

Combination of once-weekly hemodialysis with peritoneal dialysis, as in our case, reduce manipulation of the IATDC which can lower related risks and enhance median survival, but not indicated often although it has proven efficiency. [23, 24]

In fact, bimodal dialysis is associated with lower vascular access infection, and lower all-cause mortality compared with PD [25-27] This therapy is widely used in Japan (20\% of all PD patients) [27]. Our experience with bimodal dialysis lasted for nine months before switching patient to exclusive hemodialysis.

There are innumerable publications that approved PD as renal replacement therapy, but few data about the outcomes of anuric patients on PD, or about life expectancy when transferred from HD [28].

\section{Conclusion:}

Vascular exhaustion is a big challenge for nephrologists. The uncommon TDC can be used. But complications related to this type of catheters should be more frequent and consequently lower survival time. For this, we reported bimodal dialysis as another alternative to get better survival period. Based on our experience, we propose the following algorithm for management of ESRD [Figure 3]. 


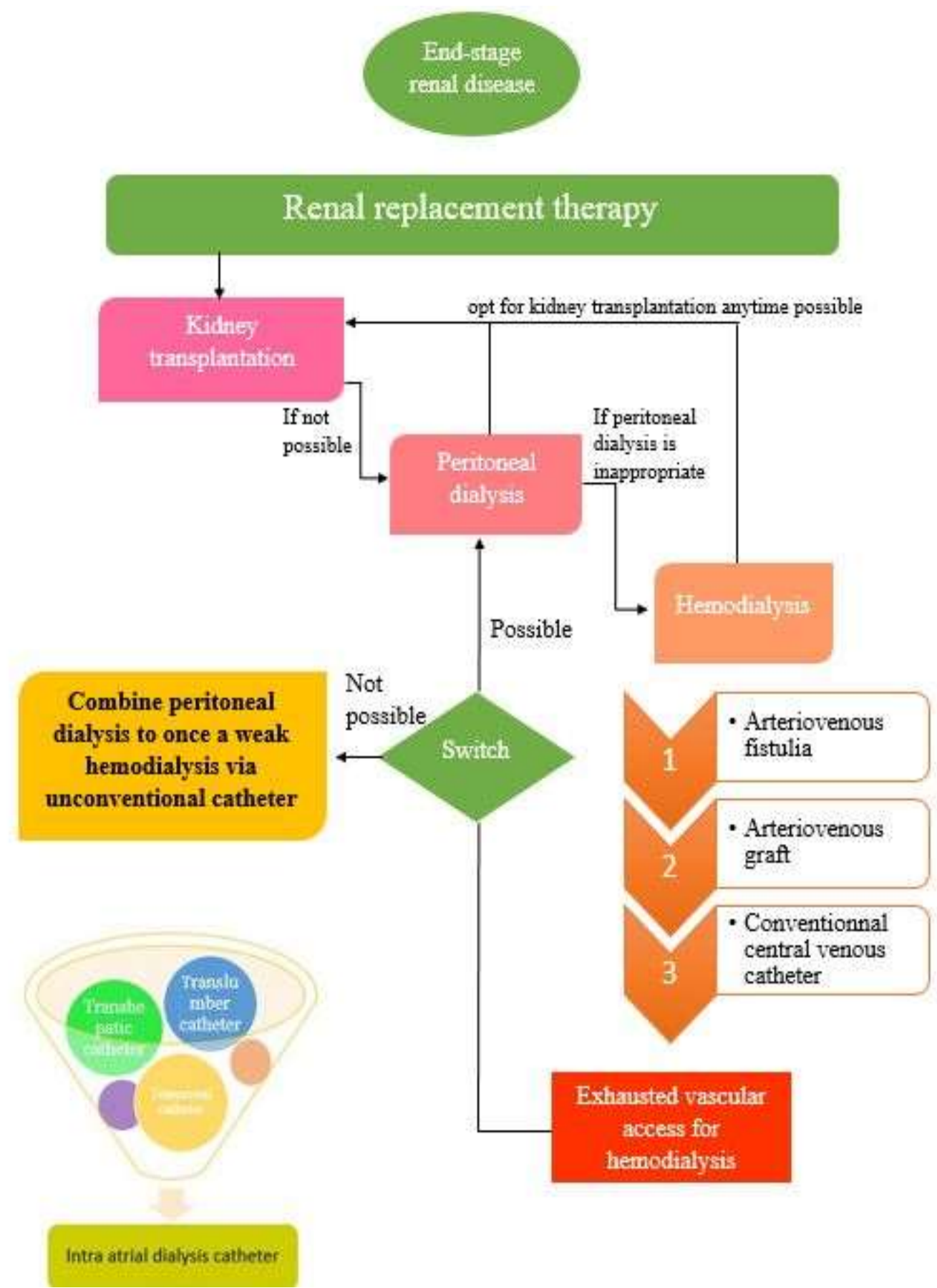

Figure 3: Renal Replacement Therapy Algorithm

\section{Conflict of interest}

No Conflits of interest

\section{References}

1. Borzych-Duzalka D, Shroff R, Ariceta G, Yap YC, Paglialonga F, Xu H, Kang HG, Thumfart J, Aysun KB, Stefanidis CJ et al: Vascular Access Choice, Complications, and Outcomes in Children on Maintenance Hemodialysis: Findings From the International Pediatric Hemodialysis Network (IPHN) Registry. American journal of kidney diseases : the official journal of the National Kidney Foundation 2019, 74(2):193202.

2. Gunawansa N, Sudusinghe DH, Wijayaratne DR: Hemodialysis Catheter-Related Central Venous Thrombosis: Clinical Approach to Evaluation and Management. Annals of vascular surgery 2018, 51:298-305.

3. Liebman SE, Chang EY: An analysis of central venous catheter-based hemodialysis starts.Clinical nephrology 2019, 92(1):9-14.

4. Al Shakarchi J, Nath J, McGrogan D, Khawaja A, Field M, Jones RG, Inston N: End-stage vascular access failure: can we 
define and can we classify? Clinical kidney journal 2015, 8(5):590-593.

5. Agarwal AK, Haddad NJ, Vachharajani TJ, Asif A: Innovations in vascular access for hemodialysis. Kidney Int 2019, 95(5):1053-1063.

6. Vachharajani TJ, Agarwal AK, Asif A: Vascular access of last resort. Kidney Int 2018, 93(4):797-802.

7. Philipponnet C, Aniort J, Pereira B, Azarnouch K, HadjAbdelkader M, Chabrot P, Heng AE, Souweine B: Systematic Review of Atrial Vascular Access for Dialysis Catheter. Kidney international reports 2020, 5(7):1000-1006.

8. van der Tol A, Lameire N, Morton RL, Van Biesen W, Vanholder R: An International Analysis of Dialysis Services Reimbursement. Clinical journal of the American Society of Nephrology : CJASN 2019, 14(1):84-93.

9. Saran R, Robinson B, Abbott KC, Agodoa LYC, BraggGresham J, Balkrishnan R, Bhave N, Dietrich X, Ding Z, Eggers PW et al: US Renal Data System 2018 Annual Data Report: Epidemiology of Kidney Disease in the United States. American journal of kidney diseases : the official journal of the National Kidney Foundation 2019, 73(3 Suppl 1):A7-a8.

10. Wall C, Moore J, Thachil J: Catheter-related thrombosis: A practical approach. Journal of the Intensive Care Society 2016, 17(2):160-167.

11. Mandel-Shorer N, Tzvi-Behr S, Harvey E, Revel-Vilk S: Central venous catheter-related venous thrombosis in children with end-stage renal disease undergoing hemodialysis. Thrombosis research 2018, 172:150-157.

12. Yates PJ, Barlow AD, Johari Y, Doughman T, Nicholson ML: The great saphenous vein for central venous access and haemodialysis. Nephrology, dialysis, transplantation : official publication of the European Dialysis and Transplant Association - European Renal Association 2009, 24(1):208210.

13. Moura F, Guedes FL, Dantas Y, Maia AH, Oliveira RA, Quintiliano A: Translumbar hemodialysis long-term catheters: an alternative for vascular access failure. Jornal brasileiro de nefrologia : 'orgao oficial de Sociedades Brasileira e LatinoAmericana de Nefrologia 2019, 41(1):89-94.

14. Rahman S, Kuban JD: Dialysis Catheter Placement in Patients With Exhausted Access. Techniques in vascular and interventional radiology 2017, 20(1):65-74.

15. Lund GB, Trerotola SO, Scheel PJ, Jr.: Percutaneous translumbar inferior vena cava cannulation for hemodialysis. American journal of kidney diseases : the official journal of the National Kidney Foundation 1995, 25(5):732-737.

16. Liu F, Bennett S, Arrigain S, Schold J, Heyka R, McLennan G, Navaneethan SD: Patency and Complications of Translumbar Dialysis Catheters. Seminars in dialysis 2015, 28(4):E41-47.

17. Chavanon O, Maurizi-Balzan J, Chavanis N, Morel B, Blin D: Successful prolonged use of an intracardiac catheter for dialysis. Nephrology, dialysis, transplantation : official publication of the European Dialysis and Transplant Association - European Renal Association 1999, 14(8):20152016.

18. Agrawal S, Alaly JR, Misra M: Intracardiac access for hemodialysis: a case series. Hemodialysis international International Symposium on Home Hemodialysis 2009, 13 Suppl 1:S18-23.

19. Asif A, Costanzo EJ, Sadiang-Abay E: Intra-atrial catheter: a viable option for insertion beyond the central veins. Jornal brasileiro de nefrologia : 'orgao oficial de Sociedades Brasileira e Latino-Americana de Nefrologia 2017, 39(2):98-99.

20. Villagrán Medinilla E, Carnero M, Silva JA, Rodríguez JE: Right intra-atrial catheter insertion at the end stage of peripheral vascular access for dialysis. Interactive cardiovascular and thoracic surgery 2011, 12(4):648-649.

21. Oguz E, Ozturk P, Erkul S, Calkavur T: Right intra-atrial catheter placement for hemodialysis in patients with multiple venous failure. Hemodialysis international International Symposium on Home Hemodialysis 2012, 16(2):306-309.

22. Malas MB, Canner JK, Hicks CW, Arhuidese IJ, Zarkowsky DS, Qazi U, Schneider EB, Black JH, 3rd, Segev DL, Freischlag JA: Trends in incident hemodialysis access and mortality. JAMA surgery 2015, 150(5):441-448.

23. Maruyama Y, Yokoyama K: Clinical efficacy of combined therapy with peritoneal dialysis and hemodialysis. Renal Replacement Therapy 2016, 2(1):11.

24. Chung MC, Yu TM, Wu MJ, Chuang YW, Muo CH, Chen $\mathrm{CH}$, Chang $\mathrm{CH}$, Shieh JJ, Hung PH, Chen JW et al: Is combined peritoneal dialysis and hemodialysis redundant? A nationwide study from Taiwan. BMC nephrology 2020, 21(1):348.

25. Kawanishi H, McIntyre C: Complementary use of peritoneal and hemodialysis: therapeutic synergies in the treatment of endstage renal failure patients. Kidney international Supplement 2008(108):S63-67.

26. Murashima M, Hamano T, Abe M, Masakane I: Combination of once-weekly haemodialysis with peritoneal dialysis is associated with lower mortality compared with peritoneal dialysis alone: a longitudinal study. Clinical kidney journal 2021, 14(6):1610-1617.

27. Maruyama Y, Yokoyama K, Nakayama M, Higuchi C, Sanaka T, Tanaka Y, Sakai K, Mizuiri S, Otsuka Y, Kuriyama S et al: Combined therapy with peritoneal dialysis and hemodialysis: a multicenter retrospective observational cohort study in Japan. Blood purification 2014, 38(2):149-153.

28. Brown EA, Davies SJ, Rutherford P, Meeus F, Borras M, Riegel W, Divino Filho JC, Vonesh E, van Bree M: Survival of functionally anuric patients on automated peritoneal dialysis: the European APD Outcome Study. J Am Soc Nephrol 2003, 14(11):2948-2957. 
(c) (†)

This work is licensed under Creative

Commons Attribution 4.0 License

To Submit Your Article Click Here: Submit Manuscript

DOI: $10.31579 / 2639-4162 / 052$
Ready to submit your research? Choose Auctores and benefit from:

$>$ fast, convenient online submission

$>$ rigorous peer review by experienced research in your field

$>$ rapid publication on acceptance

$>$ authors retain copyrights

$>$ unique DOI for all articles

$>$ immediate, unrestricted online access

At Auctores, research is always in progress.

Learn more https://auctoresonline.org/journals/general-medicine-andclinical-practice 